
9 (1981) 54
J. Perinat. Med.

\section{The accuracy of ultrasonic fetal cardiography}

\author{
T. Solum, I. Ingemarsson, $\AA$. Nygren
}

Department of Obstetrics and Gynecology, University Hospital, and Department of Electric Measurement, Lund's Institute of Technology, University of Lund, Sweden

\section{Introduction}

The DOPPLER principle is used in recording fetal heart beats by the ultrasonic technique [1]. By measuring the time intervals between the beats, the fetal heart rate can be calculated. When this calculation is done for each beat-to-beat interval, information about the instananeous fetal heart rate is obtained. A continuous writing of the instantaneous fetal heart rate produces a diagram of the beat-to-beat variability. Such diagrams are considered an important source in judging the fetal condition [4]. The variations of the ultrasound signal as reflected from different structures of the fetal heart, however, make true beat-to-beat registrations difficult. Cardiotocographs integrating, for instance, 3 beat intervals in calculating the number of beats per minute (bpm) has therefore been constructed (HP $8030 \mathrm{~A}$ ), but with this principle the beat-to-beat-information is necessarily lost. Even if the cardiograph is constructed for beat-to-beat calculations, diagrams often including the so-called jitter are produced simulating a falsely good fetal heart rate variability $[6,8]$ (Fig. 1). It is therefore questionable whether the ultrasonic fetal cardiography (uFCG) can be used in interpretation of the fetal heart rate variability $[4,6,7,11]$.

As the UFCG is the most widely used method for indirect cardiography [6], it is of importance to know the exact capacity of the UFCG in reflecting the fetal heart rate variability. The aim of the present study was to investigate the quality of the uFCG concerning both short term variability (STV) and long term variability (LTV).

\section{Material and methods}

Five patients at term were studied. They were monitored in early labour with a narrow beam ultrasound transducer (HEwLETT PACKARD 15274 A). Only those with a visually good tracing were included in the investigation (Fig. 2). After rupture of the membranes, a scalp electrode was inserted. The patients were monitored for about 25 minutes each, using two cardiotocographs, one for UFCG and one for direct fetal electrocardiography (dFECG). The cardiotocograph used for uFCG was HP 8030A Option No. 001 allowing beat-to-beat calculation. Both signals were simultaneously stored on a tape using an analogue FM tape-recorder (Hewlett-Packard 3960). The recorded signal was the $120 \mathrm{~ms}+6.5 \mathrm{~V}$ flash pulse, which is accessible in the rear system connector pin D and A (digital ground). This flash is triggered by each fetal heart beat detected by the transducer or electrode.

Two 15-bit digital counters were available for analogue-digital converson and transformation of the information into a computer. The counters measured, with $1 \mathrm{~ms}$ resolution, the beat-to-beat distance in the UFCG and dFECG channels simult-

033-5577/81/0009-0006\$02.00

(c) by Walter de Gruyter \& Co. - Berlin · New York 

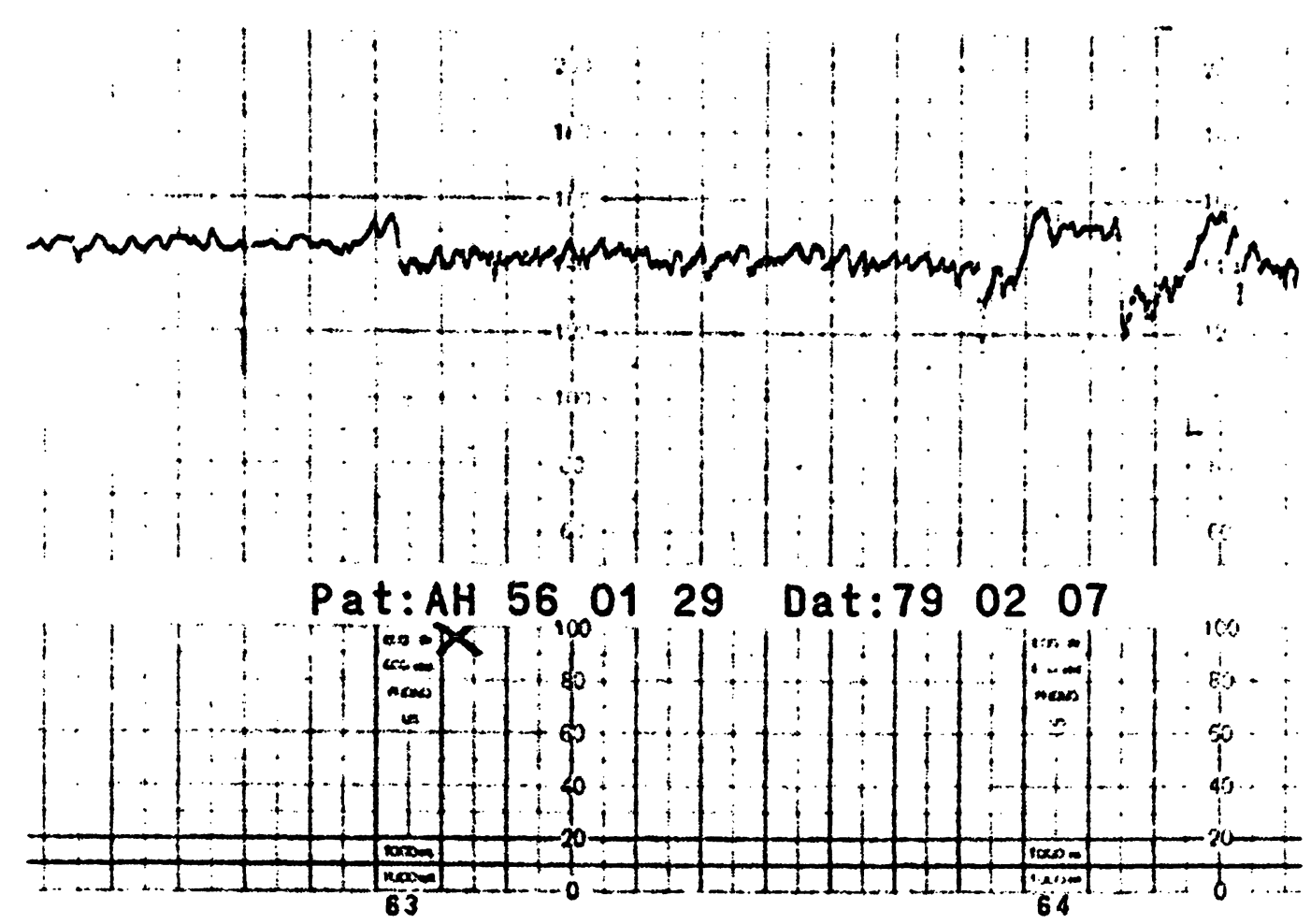

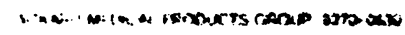
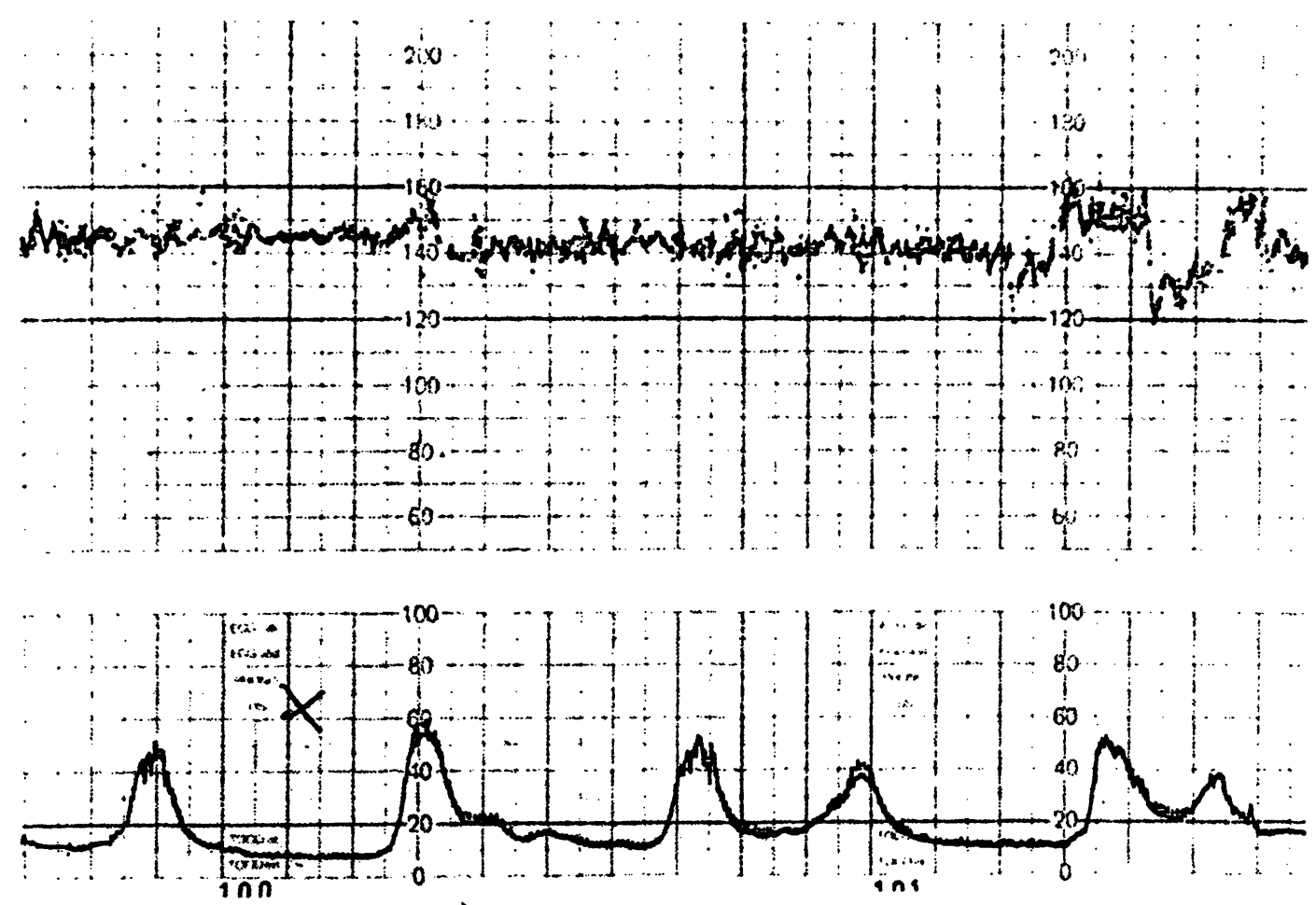

Fig. 1. Typical "jitter" on ultrasound cardiogramme (bottom) simulating a better variability than in direct cardiogramme (top). 


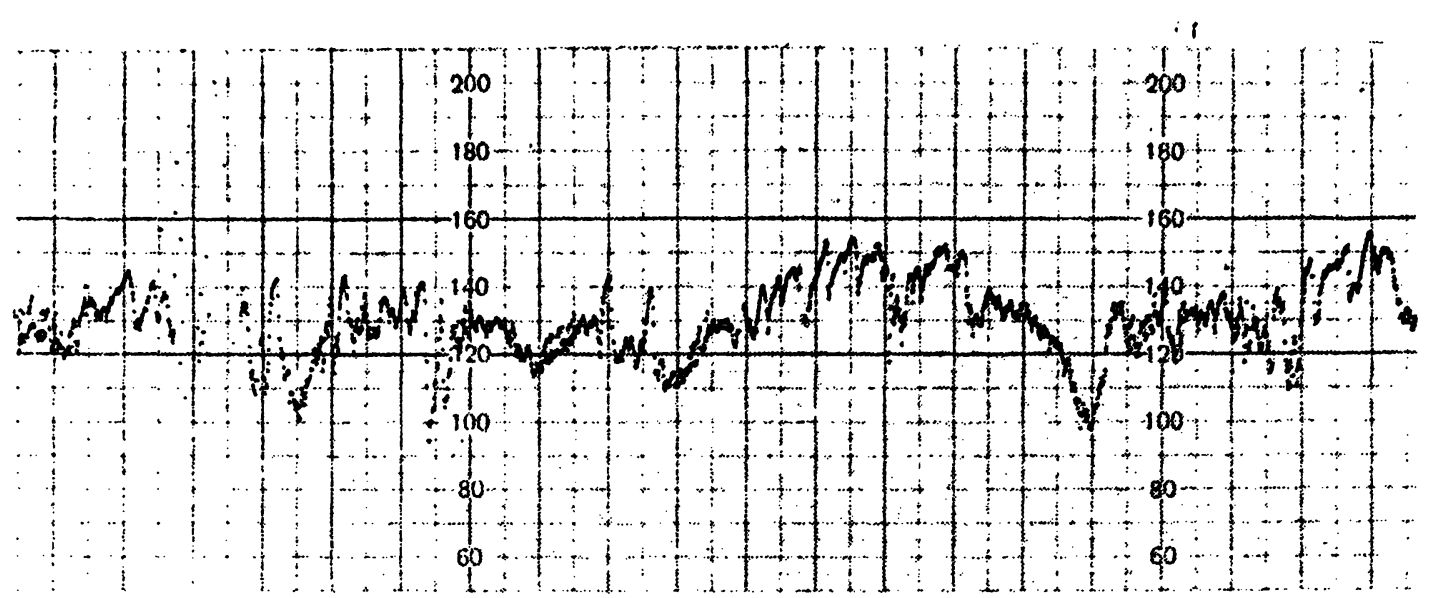

Pat: I $\begin{array}{lllll}49 & 05 & 12 & \text { Dat:79 } 09 & 05\end{array}$
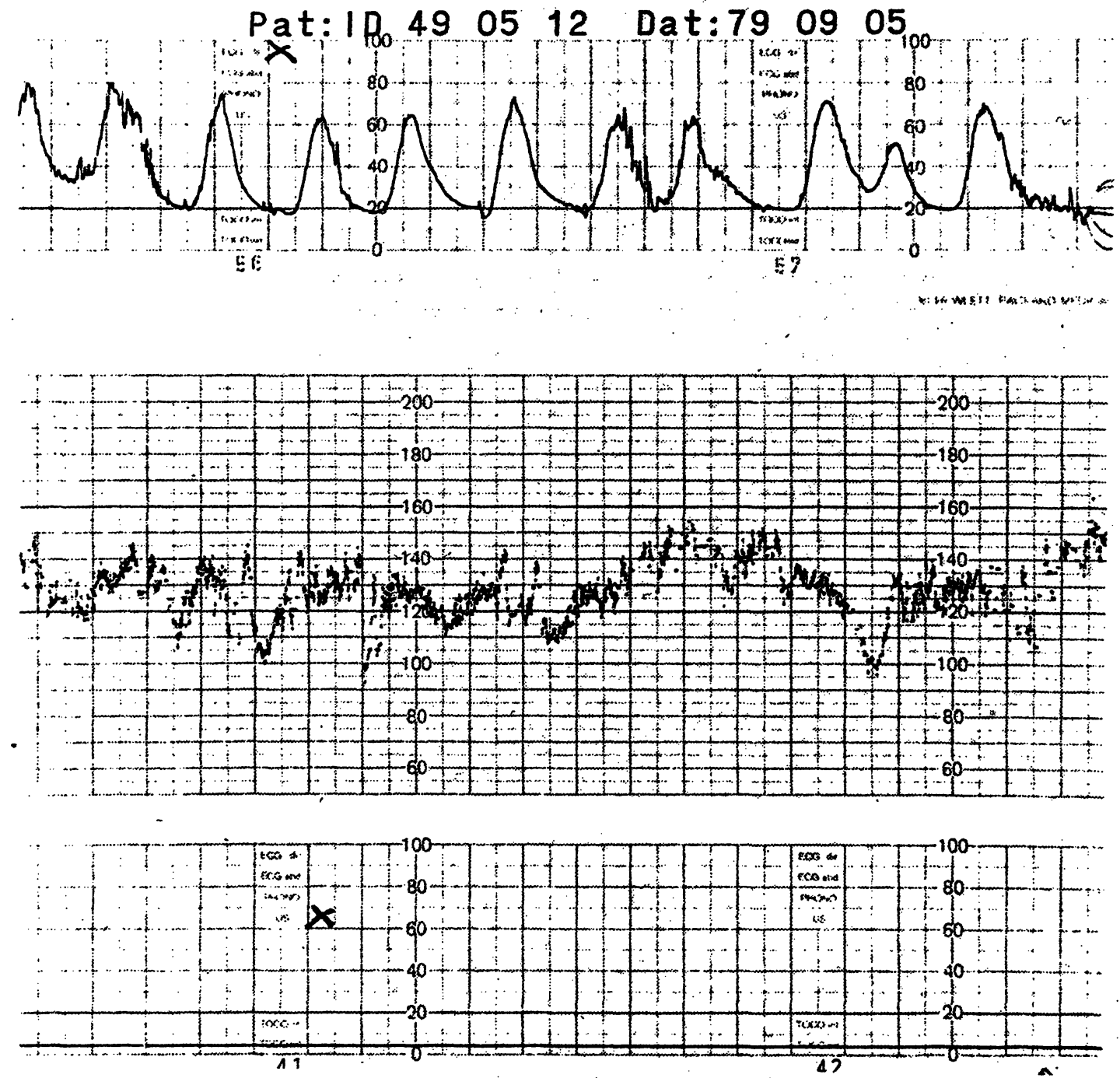

Fig. 2. An exampel of an ultrasound cardiogramme of good quality (bottom). Direct cardiogramme for comparison is shown on the top. 


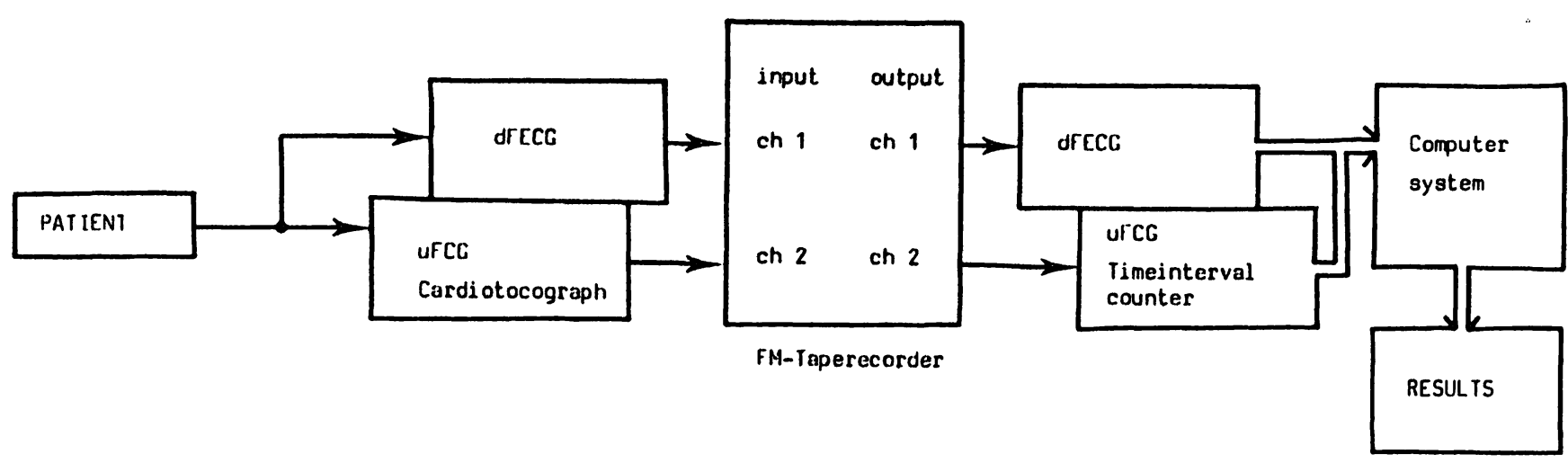

Fig. 3. Using two cardiotocographs the direct fetal electrocardiogramme (dFECG) and the ultrasonic fetal cardiogramme (uFCG) were recorded simultaneously. After storing on a tape recorder the data were processed in a computer system.

aneously using the same clock to eliminate time errors. The times measured between the beats were stored on two separate disc files for future calculations. The Data General Nova ${ }^{\circledR} 2.10$ System was used for the calculations (Fig. 3).

Around each pulse identified as a fetal heart beat by $\mathrm{UFCG}$, the dFECG channel was checked for pulses within a window of $100 \mathrm{~ms}( \pm 50 \mathrm{~ms})$, and the differences in time between each uFCG-pulse and dFECG-pulse were registered. The proportion of pulses within \pm 10 ms was calculated manually. The STV was compared allowing differences of 1 to $5 \mathrm{bpm}$ between uFCG and dFECG, and the LTV allowing differences of 1 and $2 \mathrm{bpm}$, respectively. For calculation of the two types of variability, the indices of DE HAAN were chosen [3]. The results are expressed by means of the correlation coefficient.

\section{Results}

In mean, 3191 fetal heart beats from each patient were registered by dFECG; a total of 15955 beats. The computerized comparison of dFECG and uFCG showed that only 11552 beats $(72.4 \%)$ had been registered by UFCG, although only tracings of good visual quality were included (Fig. 2).

Around each registered uFCG-pulse, the dFECGfile was checked within a window of $100 \mathrm{~ms}$ ( $\pm 50 \mathrm{~ms}$ ). A corresponding dFECG-pulse could be found in $86.2 \%$ of the 11552 uFCG-pulses. Differences within the cases ranged from $74.8 \%$ to $98.8 \%$ (Tab. I). Within a window of $\pm 10 \mathrm{~ms}$, only $61.4 \%$ (7093) of the pulses could be found (Fig. 4).
Tab. I. The number of dFECG-pulses found within $\pm 50 \mathrm{~ms}$ around each uFCG-pulse.

\begin{tabular}{llll}
\hline Patient No. & $\begin{array}{l}\text { Total number } \\
\text { of beats } \\
\text { by uFCG }\end{array}$ & \multicolumn{2}{l}{$\begin{array}{l}\text { Number of beats within } \\
\text { a distribution } \\
\text { of } \pm 50 \mathrm{~ms}\end{array}$} \\
\hline 1 & 1962 & 1552 & $(79.1 \%)$ \\
2 & 2358 & 1925 & $(81.6 \%)$ \\
3 & 1546 & 1406 & $(90.9 \%)$ \\
4 & 2250 & 1683 & $(74.8 \%)$ \\
5 & 3436 & 3396 & $(98.8 \%)$ \\
Total & 11552 & 9962 & $(86.2 \%)$ \\
\hline
\end{tabular}

Comparing the STV recorded by the two methods, differences of 1 to $5 \mathrm{bpm}$ were allowed. The correlations between UFCG and AFECG for all beats resulted in coefficients from 0.32 to 0.78 (Tab. II, Fig. 5). The LTV was compared allowing differences of only 1 and $2 \mathrm{bpm}$. The correlation coefficient in the first case was 0.50 , in mean, for all 11552 beats, and 0.70 in the latter case (Tab. III, Fig. 6).

Tab. II. Correlation in short term variability (STV) between uFCG and dFECG allowing differences of 1 and 5 bpm, respectively.

Patient No. Correlation coefficients at a difference of $1 \mathrm{bpm} 5 \mathrm{bpm}$

\begin{tabular}{lll}
\hline 1 & 0.32 & 0.75 \\
2 & 0.36 & 0.80 \\
3 & 0.34 & 0.79 \\
4 & 0.25 & 0.68 \\
5 & 0.40 & 0.86 \\
Mean for all patients & 0.32 & 0.78 \\
\hline
\end{tabular}




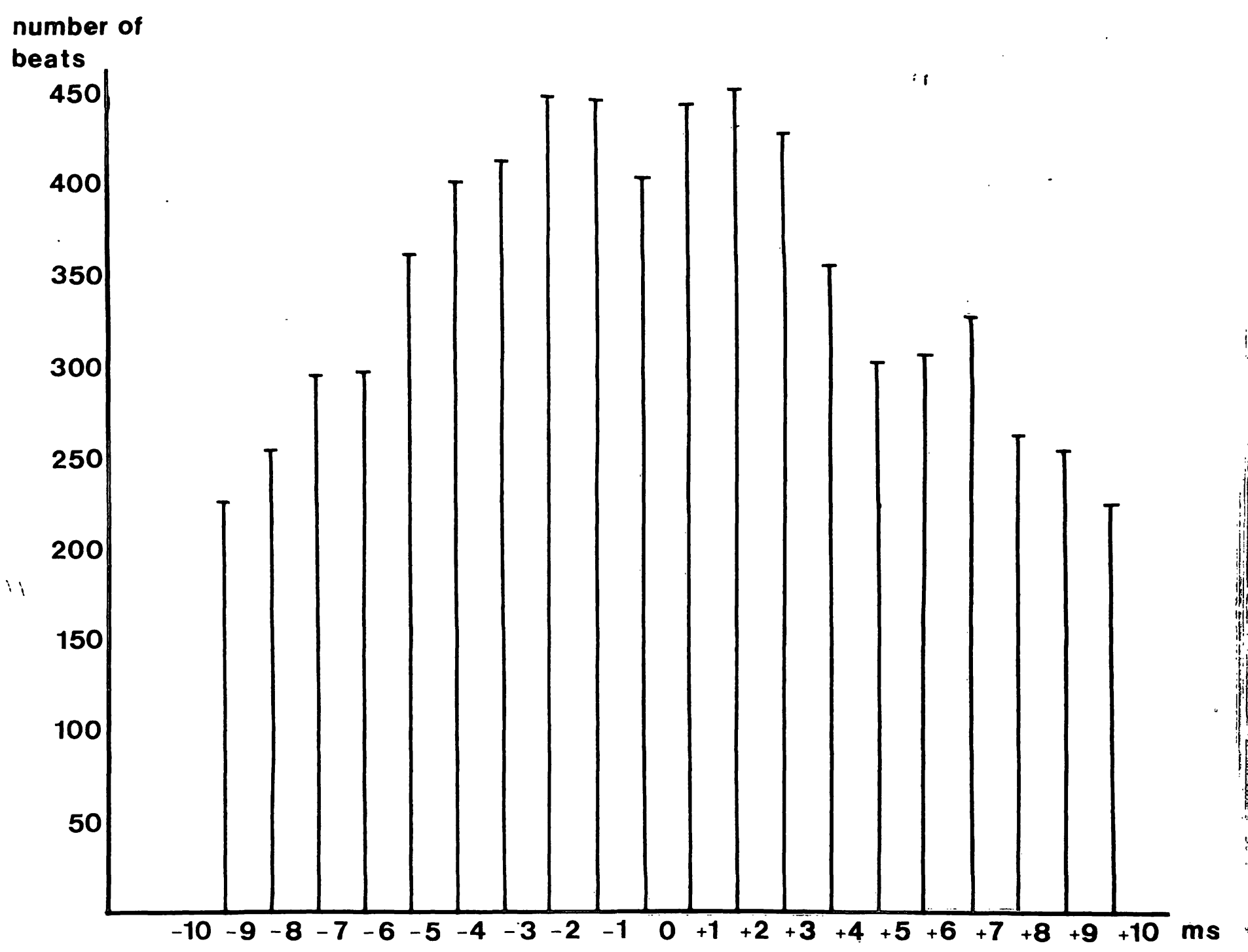

Fig. 4. 61.4\% of all pulses registered by ultrasound fetal cardiography (UFCG) were found within $\pm 10 \mathrm{~ms}$ around the pulses registered by direct fetal electrocardiography (dFECG). The abscissa shows the time relation between uFCG and dFECG, the ordinate the number of beats registered by uFCG.

Tab. III. Correlation in long term variability (LTV) between uFCG and dFECG allowing differences of 1 and $2 \mathrm{bpm}$, respectively.

Patient No. Correlation coefficients at a difference of

\begin{tabular}{lll}
\hline & $1 \mathrm{bpm}$ & $2 \mathrm{bpm}$ \\
1 & 0.43 & 0.65 \\
2 & 0.58 & 0.77 \\
3 & 0.51 & 0.72 \\
4 & 0.45 & 0.65 \\
5 & 0.59 & 0.82 \\
Mean for all patients & 0.50 & 0.70 \\
\hline
\end{tabular}

\section{Discussion}

The variability of the fetal heart rate is fundamentally of two types [3]: One of short term changing with each heart beat, and one of longer term changed three to ten times per minute. HAMMACHER et al. [5] stressed the importance of true beat-to-beat registration of the fetal heart rate. Classifications of the variability have been proposed using four different classes from silent to saltatory patterns [5]. This type of classification has been widely used. However, comparing this visually based interpretation of the fetal heart rate 


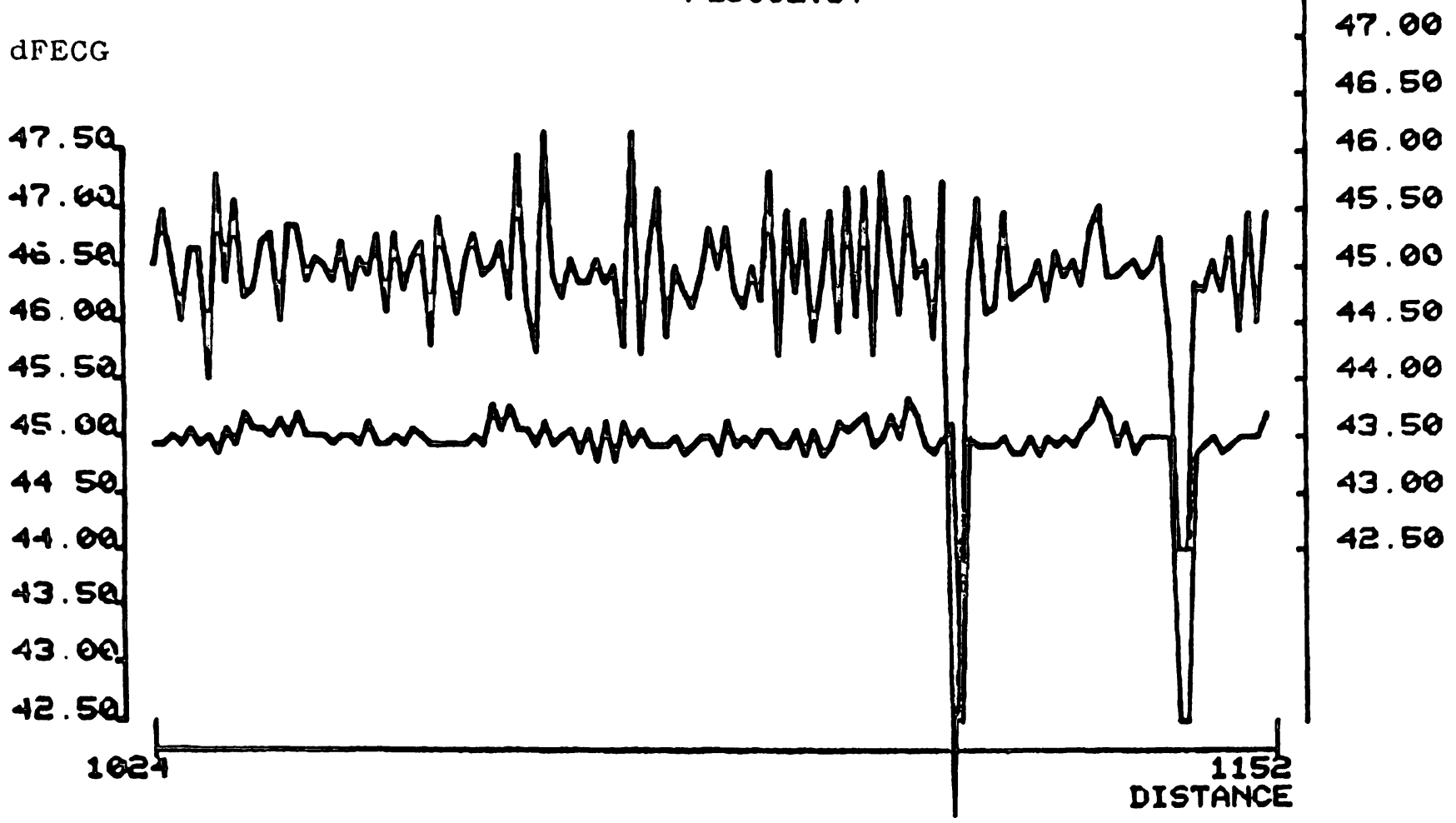

Fig. 5. A display of the short term variability (STV) made by the computer. The abscissa shows a distance of 128 beats (intervals). The left ordinate represents the different angles of the argument for dFECG according to the definition of DE HAAN. The right ordinate shows the same for uFCG (0.204 degrees mean a difference in STV of 1 bpm by a frequency of $140 \mathrm{bpm})$. The deep dips represent artifacts.

variability with computer aided interpretation shows that visually the long term variability, rather than the short term variability, is perceived $[7,9]$. With uFCG, two main problems exist in judging the variability: The variation of the ultrasonic signal itself resulting in difficulties in measuring the correct beat-to-beat interval; the electronic adaptation of artifacts produces "jitter" resulting in a false impression of good variability. Usually, however, the existence of "jitter" can be visually identified [11]. Fig. 1 shows an example.

The results of the present study show that a difference of $1 \mathrm{bpm}$ in STV between uFCG and dFECG results in a correlation coefficient of 0.32 . To achieve a correlation coefficient of 0.78 , as great a difference as $5 \mathrm{bpm}$ must be allowed. This poor correlation indicates that UFCG can hardly be used in interpretation of STV. A better correlation con- cerning LTV was found. The correlation coefficient between uFCG and dFECG was 0.70 accepting a difference of $2 \mathrm{bpm}$. However, what constitutes a sufficient correlation and what accuracy should be required is open to question.

As mentioned above, the STV can hardly be recognized visually and the correct interpretation must therefore be based on computer calculation. Previously [10], the abdominal electrocardiography (aFECG) was studied. It could be concluded that the aFECG-signals was of high quality and allowed a computerized interpretation of the STV. The investigation of UFCG indicates that computerized interpretation of STV by this method is too inaccurate.

The LTV recorded by aFECG was almost identical with dFECG [10]. Registrations of corresponding accuracy could not be demonstrated by uFCG; but 


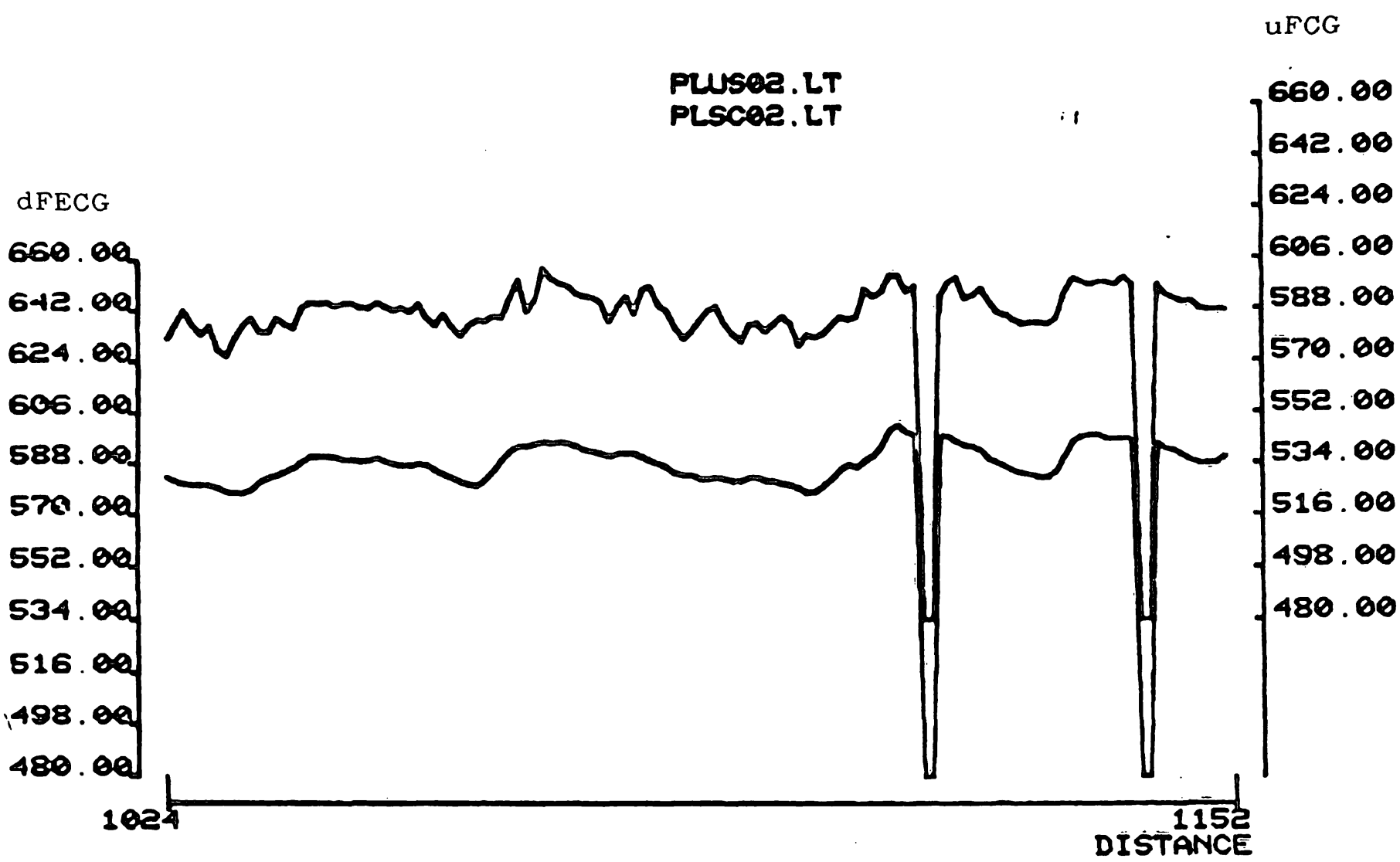

Fig. 6. A display of the long term variability (LTV) made by the computer. The abscissa shows a distance of 128 beats (intervals). The left ordinate represents the different moduli for dFECG according to the definition of DE HAAN. The right ordinate shows the same for uFCG (3.4 ms mean a difference in LTV of $1 \mathrm{bpm}$ by a frequency of $140 \mathrm{bpm}$ ). The deep dips represent artifacts.

compared with STV, the correlation was relatively good. Thus it seems possible to use uFCG for visual interpretation of the fetal heart rate provided that "jitter" is absent. The aFECG can hardly be used between the 28th and the 34th week of gestation [2]; even in the last weeks of pregnancy, the uFCG is used routinely in ante-

\section{Summary}

The present work investigated the accuracy of ultrasound cardiography (UFCG) in registering the fetal heart rate variability. Five patients in early labour were studied.

Two cardiotocographs (HP 8030A) were simultaneously recording UFCG and direct fetal electrocardiography (dFECG). The information was stored on an analogue FM tape recorder for further data processing.

The number of beats registered by the two methods were counted, and the time intervals between the beats were calculated. The short term variability (STV) and the long term variability (LTV) were investigated according to the definitions of DE HAAN [3]. natal monitoring because it is easy to handle [6, 8]. Therefore uFCG can be used with certain limitation in visually judging the fetal heart rate variability, but the aFECG should be used as often as possible for a more reliable registration of the fetal heart rate variability.

To get an acceptable correlation coefficient in STV of 0.78 , a difference as high as 5 beats per minute (bpm) between the two registrations had to be allowed. For LTV, a correlation coefficient of 0.70 was reached at a difference of $2 \mathrm{bpm}$.

The results of the study show that the uFCG can hardly be used in interpretation of the STV. As the visual examination of the cardiotocograms reflects the LTV rather than the STV $[7,9]$, the UFCG can be used for interpretation of LTV provided that "jitter" is absent on the tracing.

Keywords: Fetal heart, fetal monitoring, long term vạriability, short term variability, ultrasound. 


\section{Zusammenfassung}

Die Genauigkeit fetaler Ultraschallkardiographie

In der vorliegenden Studie wurde die Genauigkeit der Ultraschallkardiographie (uFCG) in der Darstellung der Variabilität der fetalen Herzfrequenz untersucht.

Es wurden 5 Kreißende im ersten Stadium des Geburtsverlaufes untersucht. Zwei Kardiotokographen (HP 8030A) wurden an jeder Patientin angeschlossen, um simultan uFCG und direkte, fetale Elektrokardiographie (dFECG) zu registrieren. Diese Information wurde analog auf einen FM Bandspieler aufgenommen und später an einen Computer geleitet.

Die von beiden Methoden registrierte Anzahl der Herzschläge wurde gezählt, und die Zeitrelationen zwischen den Schlägen wurden berechnet. Wie von DE HAAN [3] vorgeschlagen, wurden Mikro- und Makrofluktuationen bestimmt und verglichen.
Um eine akzeptable Korrelation der Mikrofluktuation von $0.78 \mathrm{zu}$ erzielen, mußte ein Unterschied von 5 Herzschlägen pro Minute (bpM) zwischen uFCG und dFECG zugelassen werden. Bei einem Unterschied von 2 bpM wurde für die Makrofluktuation eine Korrelationskoeffizienz von 0.70 erzielt.

Die Resultate der Studie zeigen, daß uFCG kaum für die Interpretation von Mikrofluktuation benutzt werden kann. Die visuelle Untersuchung eines Kardiotokogramms aber, ermöglicht vermutlich nur, die Makrofluktuation zu beurteilen $[7,9]$. Vorausgesetzt, daß kein ,jitter" auf dem Diagramm vorhanden ist, ist deshalb uFCG für die Interpretation der Makrofluktuation ausreichend.

Schlüsselwörter: Fetales Herz, fetale Überwachung, Makrofluktuation, Mikrofluktuation, Ultraschall.

\section{Résumé}

\section{La précision de la cardiographie foetale à ultrasons}

L'objet de la présente étude concerne la précision de la cardiographie à ultrasons (uFCG) pour l'enregistrement de la variabilité du rythme cardiaque foetal. On a étude 5 patients en début de travail. Deux cardiotocographes (HP 8030A) ont enregistré simultanément l'uFCG et l'électrocardiographie foetale directe (dFECG).

L'information a été stockée sur un magnétophone FM analogique pour traitement ultérieur sur ordinateur.

Le nombre de battements enregistrès par les ceux méthodes a été compté de même qu'a été calculée la durée de l'intervalle séparant les battements. On a étudié la variabilité à court terme (STV) et celle à long terme (LTV) ensuivant les définitions de DE HAAN [3]. Pour obtenir un coefficient de corrélation acceptable de 0.78 pour la STV on a du admettre une différence qui s'élève jusqu'à 5 battements par minutes (bpm) entre les deux enregistrements. Pour la LTV un coefficient de 0.70 a été atteint pour une différence de $2 \mathrm{bpm}$.

Les résultats de l'étude montrent que l'uFCG peut pas vraiment être utilisée pour l'interprétation de la STV. Comme l'examen visuel des cardiotocogrammes reflète plutôt les LTV que les STV [7, 9] l'uFCG peut être utilisée pour l'interprétation de la LTV pourvu que le «jitter» soit absent du tracé.

Mots-clés: Rythme cardiaque foetal, surveillance foetale, ultrasons, variabilité à court terme, variabilité à long terme.

Acknowledgements: We thank Professor HELlmUTH HERTZ, Head of the Department of Electrical Measurement of the Lund Institute of Technology for his kind support of the project.

We also thank Dipl. Ing. RIKARD BLOM for making the figures displaying the variability.

\section{Bibliography}

[1] BISHOP, E. H.: Obstetric uses of the ultrasonic motion sensor. Amer. J. Obstet. Gynec. 96 (1966) 863

[2] BOLTE, A.: Die pränatale fetale Elektrokardiographie. Gynäkologe 2 (1969) 63

[3] DE HAAN, J., J. H. VAN BEMMEL, B:VERSTEEG, A. F. L. VETH, L. A. M. STOLTE, J. JANSSENS, T. K. A. B. ESKES: Quantitative evaluation of fetal heart rate patterns. Eur. J. Obstet. Gynec. 3 (1971) 95

[4] HAMMACHER, K.: Elektronische Geburtsüberwachung. Med. Klin. 64 (1969) 1846
[5] HAMMACHER, K., K. A. HÜTER, J. BOKELMANN, P. H. WERNERS: Foetal heart frequency and perinatal condition of the foetus and newborn. Gynaecologia 166 (1968) 349

[6] HON, E. H., R. H. PETRIE: Clinical value of fetal heart rate monitoring. Clin. Obstet. Gynec. 18 (1975) 1

[7] KARINIEMI, V.: Evaluation of fetal heart rate variability by a visual semiquantitative method and by a quantitative statistical method with the use of a minicomputer. Amer. J. Obstet. Gynec. 130 (1978) 588 
[8] KLÖCK, F. K., L. HARTMER: Die Kardiotokographie mit dem externen fetalen EKG im Vergleich zur Ultraschallkardiotokographie. Z. Geburtshilfe Perinat. 181 (1977) 178

[9] LAROS, R. K., W. S. WONG, D. C. HEILBRON, J. T. PARKER, S. M. SHNIDER, H. NAYLOR, J. BUTLER: A comparison of methods for quantitating fetal heart rate variability. Amer. J. Obstet. Gynec. 128 (1977) 381
[10] SOLUM, T., I. INGEMARSSON, A. NYGREN: The accuracy of abdominal ECG for fetal electronic monitoring. J. Perinat. Med. 8 (1980) 142

[11] WHEELER, T., P. GUERARD: Fetal heart rate during late pregnancy. J. Obstet. Gynaec. Brit. Cwlth. 84 (1974) 348

Received March 24, 1980. Accepted July 18, 1980.

Dr Thore Solum

Department of Obstetrics and Gynecology University Hospital

S-22185 LUND Sweden 